\title{
AFRICAN MANPOWER PLANS: AN EVALUATION
}

\author{
Richard Jolly*
}

This report summarizes a study evaluating 38 African manpower plans, prepared in twenty-three African countries during the period 1959-70. ${ }^{1}$ The key question in our evaluation was the following: 'In the light of subsequent experience, how adequate were the various manpower studies in their attempts to estimate the future demand for educated manpower?' In addition, our evaluation attempted to assess the relevance of manpower planning to a wider range of policy issues, past and future, and to suggest how its usefulness to policymakers might be improved.

In assessing these plans and drawing conclusions for manpower planning today, it is important not to lose sight of the context in which the work was originally undertaken. African manpower plans of the early 1960s were almost all prepared in a period of acute manpower shortage when the main concerns of policy makers were how to expand what are now seen as essentially colonial educational systems to meet the demands of independence and in particular, to meet the urgent need for localizing high level posts predominantly held by expatriates. Today in most of Africa the problems are markedly different. Almost all of the top government posts and a high proportion of the top posts in the rest of the public sector and in the private sector are held by nationals. Shortages of manpower have given way to surpluses among secondary school leavers and often in North and West Africa among university graduates.

Most important - and more significant - there is today a more critical awareness of the deficiencies of the educational systems and of the

\footnotetext{
* Richard Jolly is Director and Professorial Fellow of the Institute of Development Studies.

1 The study also examined ten rate of return studies prepared in Africa over the same period but for reasons of space they are not reported on here. A detailed report of the study is given in A.R. Jolly and Christopher Colclough, 'African Manpower Plans: an evaluation', International Labour Review, vol. 106 no. 2/3, August/September 1972, and reprinted in Employment in Africa: some critical issues, ILO, 1973. The original study was supported by a grant from the Ministry of Overseas Development.
} 
need for a new and broader approach to educational planning. It is increasingly realised that the qualitative weaknesses of education are just as serious as the quantitative weaknesses and probably more difficult to remedy. Many commentators now agree that the role which educational systems have actually played in development in Africa and outside is very different from that originally conceived. Instead of providing training which prepares people for high-level work, education sometimes has served as little more than a means of rationing the certificates needed to enter the best jobs. The expansion of university places, instead of being a move towards greater equality, has often interacted with wide differentials in salary scales to create an educated elite.

More fundamental still, disillusionment with many aspects of the formal educational system is going hand in hand with a rediscovery of the potential value of non-formal and informal education. What is learnt outside school - on the farm, in the village, in apprenticeship, on the job, in the home and in a multitude of other forms of learning (many not conventionally thought of as education at all) - may add up to a more significant accumulation of knowledge and intellectual development than is acquired in the classroom. This shift of focus not only directs attention to different types of education but also suggests that measures to develop the school and university may in effect often have acted to retard and distort other, possibly more efficient forms of education.

All these changes call in question much of what has previously been done in the name of manpower planning. Reconstruction is necessary, though in our view many of the earlier building blocks will remain. But first one must ascertain what was done - and how reasonable it was in its context. We turn therefore to the objectives, methodology and lessons to be drawn from the experience of the African manpower plans of the 1960s.

\section{Objectives}

A central objective of most of the 38 African manpower plans we surveyed was to identify current shortages (not to deal with possible surpluses), to forecast the demand for skilled and educated manpower and to provide guidelines for educational expansion. In addition: 
certain subsidiary objectives were almost always involved: the examination of priorities and prospects for localizing skilled jobs, particularly in the civil service; the formulation of recruitment and immigration policy in respect of skilled expatriate manpower; and the establishment of priorities for training schemes of various sorts. A few manpower plans also directed their findings to other economic objectives - recommendations on population policy, for instance though these were generally not a central feature nor were they integrated quantitatively with the rest of the forecasts.

The most notable omission in this list of objectives was employment. Most of the manpower plans concentrated on skilled and educated manpower giving only limited attention to wage- and self-employment in general, or to work opportunities or needs in the informal sector, urban as well as rural. Other important issues neglected were incomes policy, especially the structure of incentives and future trends in the earnings of skilled and educated persons and the whole question of the allocation of the labour force, within sectors, occupations and geographical regions. It is true that a number of the manpower surveys mentioned these problems and suggested general policy approaches to deal with them. But the data, analysis and policy proposals on these other issues were in general extremely thin, particularly when compared with the time and technical effort spent on projections of skilled manpower demand.

Besides the overt economic objectives, or possibly underlying them, there were others, more directly related to the domestic and international contexts in which the plans were prepared.

Domestically, the manpower surveys served - and have been used - to document government achievements, particularly in localization, and thus to defend records of performance.

Internationally, the manpower surveys served some of the same objectives as national plans served with respect to international aid. Donor agencies asked for such surveys to identify priorities for technical assistance and educational aid. Abroad and at home, various groups with an interest in educational expansion found it useful to associate themselves with the notion of a manpower survey in the expectation that it would provide 'scientific' evidence of the need for further educational expansion. 


\section{Methodology}

The methods used to produce manpower plans directed to these objectives naturally varied, though one can identify three broad approaches. These were, first, plans undertaken according to a model originally developed in Tanzania in 1964/65 - a careful assembly of data obtained by personal interviews of all main firms and government departments, using a simple, basic questionnaire. These data were commonly used to make five year projections for the whole economy of manpower needs in some 150 occupational groups. All of the persons within each of these occupational groups were assumed to require one particular level of educational preparation. There was a second fairly homogeneous group of manpower plans, less comprehensive and more eclectic in their approach, often based on indirect estimates of the base line data on manpower supplies and making partial projections usually by broad skill group rather than either occupation or formal levels of education. Most of the plans of Franco-phone countries fall in this group. There was a third, smaller group of plans based on economically more sophisticated approaches: these involved a wider range of basic data, more sophisticated techniques, with projections sometimes extending over 10 or 15 years, occasionally supplemented by sensitivity analysis and experimenting with other approaches.

It is obviously not possible to generalize about the different methodologies used in these three groups without some distortion. Nevertheless one can see them all as more or less rough approximations to a broad projection methodology of the following sort:

table 1 Key steps and assumptions in macro-projections of the demand for and supply of skilled and educated manpower

\section{Demand Projections}

1.1 Establish base year data on employment of skilled and educated manpower (including an evaluation of reliability and coverage)

1.2 Make adjustments to correct for sub-optimality in base year employment

1.2.1 assess the relevance of vacancies (or over-staffing) 
1.2.2 assess the relevance of structural imbalances (e.g. shortage of middle-level in relation to high-level manpower)

1.2.3 assess the relevance of qualitative weaknesses in education, training or job experience

1.3 Project growth in demand

1.3.1 evaluate growth and structural change in the economy

1.3.2 evaluate assumed elasticity of growth of demand with respect to changes in output and structural change

1.3.3 evaluate changes in wage levels of educated manpower

1.3.4 evaluate assumed demand elasticity with respect to changes in wages

2 Supply Projections

2.1 Estimate base year data on employment of skilled and educated manpower

2.2 Estimate gross additions from education, training, upgrading on the job, etc.

2.3 Estimate wastage from death and migration (possibly also from retirement)

2.4 Estimate labour force participation rates

2.5 Adjust for assumed changes in hours and intensity of work

2.6 Estimate supply of non-citizens (or target proportions of requirements to be met by citizen manpower)

3 Balance, Costs and Sensitivity

3.1 Adjust supply and demand to achieve balance of stocks in target year (i.e. balance of total quantity in demand and supply at target date

3.2 Adjust supply and demand to achieve flow balance (i.e. balance of annual net additions to demand and supply at target dates)

3.3 Minimize costs of implied education and training programme

3.4 Apply sensitivity analysis showing sensitivity of policy conclusions to variations in key assumptions 
One must stress that this is a highly schematic presentation of the procedures and no single manpower plan undertook all of the steps described, let alone undertook them in exactly the way outlined. Moreover, it is a highly aggregative account and many plans rightly adopted a more disaggregative approach, giving greater emphasis to the changing manpower needs of particular sectors, sub-sectors or even particular industries or government departments. Yet with these qualifications, table 1 indicates the methodology underlying most African manpower plans, with some plans covering most steps as indicated and other plans covering only a few or tackling the issues involved in different ways.

Before turning to the results of our evaluation, a basic assumption of all the manpower plans should be mentioned. Almost all of them related their projections to growth and structural change in the economy, but with most emphasis on growth. Methodologically they assume that manpower was an essential input for production and calculated what level of skilled manpower was required to make possible a projected increase in output. Sometimes these assumptions were explicitly made by the planners, sometimes implicitly in projection built up from estimates by employers or by government departments of their future demand.

In general two main criticisms can be raised to this approach. In the first place, by concentrating solely on the economic demand for skilled and educated manpower for the skilled jobs required for a specified level of production, it ignores any additional manpower involved in the actual process of reaching that level or structure of production. Second, the simple production approach almost entirely neglects the wider effects of higher education on, for example, family structure, student attitudes (unrest), fertility and population growth, job aspirations, work attitudes, income distribution, etc. - all of which may in turn have repercussions on the development of the economy.

\section{Projecting Manpower Supply and Demand}

How accurate were the projections for future demand and supply of skilled and educated manpower? If the target date of the projections had in all cases been passed and if data had been available on the manpower situation at that date in all countries, it would have been 
possible to compare projections with outcomes and so to evaluate the accuracy of the original projections.

Unfortunately only one such case existed in Africa, that of Tanzania, where the 1964/65 five-year projections could be compared with the actual situation in $1968 / 69$ as revealed by the data given in the subsequent 1968/69 manpower survey. In the case of the other 37 manpower plans we surveyed, such a direct comparison is not possible either because the terminal date of the projections had yet to be reached ( 20 cases) or because comparable data on the manpower situation at the terminal date were not available by which to judge the accuracy of the original projections ( 17 cases $)$.

For this latter group of plans, however, it was possible to undertake an indirect evaluation. This was done by considering (a) the methodology used for the projections, and (b) the accuracy and basis of the key parameters and variables assumed in the projections judged against empirical data. This enabled us to make a partially empirical evaluation of the likely accuracy of the original projections. Even if direct comparisons of projections and outcomes had been possible an indirect evaluation of this sort would still have been needed in order to investigate the reasons for a projection's accuracy or inaccuracy and to improve projection methodology in the future. A projection may be 100 per cent accurate for the wrong reasons (e.g. by involving compensating errors in basic assumptions) or wrong for the right reasons (e.g. an accurate projection but incorrectly forecasting the outcome because other developments do not take place as planned). This is always a problem in evaluating conditional projections, in which the relationship between projections and outcome reflects the extent to which related developments in the economy have taken place as forecast or planned as well as the accuracy of the original projection methodology.

There is not space here to give the details or all the results of the full evaluation of the manpower plans. Although historical in focus, the conclusions of the evaluation are by no means of simply historical interest. They have direct relevance for the practice of manpower planning, by illuminating from experience issues which too often have only been debated theoretically in the economic literature on 
educational and manpower planning. ${ }^{2}$ One result is that work on education and manpower planning has become a thriving field for myth, accusation and counter-accusation. Some of the myths which currently go the rounds were shown by our evaluation to be misleading, if not completely erroneous. Our conclusions are here summarized in relation to some of the statements often made:

1. Manpower forecasts have been totally misleading.

In contrast, our survey showed that most of the African manpower forecasts involved errors, but as far as we could estimate these were by no means so large as to make the forecasts totally misleading. Of the 18 manpower forecasts we were able to evaluate against subsequent developments, almost all were within a range of 50 per cent of the projections based on more realistic assumptions and a quarter were within 20 per cent. (See original text for a fuller explanation of this).

By the standards of forecasting in other fields, there is no reason to think that manpower planning has performed markedly less well than projections in other economic areas.

Given the general problems of forecasting future economic trends, it is not surprising that conditional forecasts of manpower needs also involve margins of error.

Awareness of these difficulties of accurate forecasting underlines the need to use a variety of projection methods, to avoid single point forecasts, to use sensitivity analysis and to be cautious in drawing conclusions. Manpower plans are not to be thrown out of the window. Prepared with sensitivity and used with awareness of their limitations, they can offer broad guidelines.

2. The weakness of manpower planning is 'proved' by the 'over-supply' and unemployment of persons with secondary and higher education. Not true. In most African countries enrolments in secondary and higher

\footnotetext{
2 Two important exceptions are R. Hollister, A Technical Evaluation of the First Stage of the Mediterranean Regional Project, OECD, 1966; and B. Ahamad and M. Blaug, The Practice of Manpower Forecasting, Elsevier, 1973. The latter is a collection of case studies but includes only one African example.
} 
education seem to have increased during the 1960s well in excess of the needs forecast by the manpower plans. Thus over-supply or unemployment cannot be taken as evidence of faulty forecasting of needs.

3. Projections of educational supply, in contrast to projections of demand for educated manpower, are relatively straightforward. There is little room for improvement on current practice short of the introduction of very much more sophisticated, probably computerized techniques.

Again a myth. We found that outputs of the school system were usually projected in a most casual and inadequate manner. Commonly no allowance was made for repetition within the school system and occasionally drop-out was totally ignored. Rarely were any changes assumed in the projected rates of progression and drop-out within the main levels of the system. The net effect was a general underestimation of the likely magnitude of educational supply.

4. Manpower planning is in every context inferior to cost benefit calculations, both in theory and practice.

This is not the place to summarize the theoretical debates, except to state my own position that both techniques require one to swallow some awfully big assumptions, if one is even to begin the meal. The trouble is that most practitioners of either art usually develop as strong stomachs for their own type of meal, as they feign to suffer indigestion from that of the others. Most of the ten African rate of return calculations rested on appalling deficiencies of data, most notably that in none of them was there any evidence at all of agricultural non-wage incomes of farmers in the rural areas, both rural and urban unionists instead being estimated from wage data, often drawn only from the urban formal sector or from civil service wage scales. Given such data problems and the other assumptions, we concluded that one could give little credence to the calculated rates of return as indicators of the social benefits of education. In any case, what was needed was guidance on the direction and order of magnitude of non-marginal quantitative and qualitative changes in education and the whole wage structure, (not on marginal quantitative change of the existing educational system). 
5. Educational costs are already pared to the bone and there is little room for further reductions.

Although resting on evidence beyond the manpower plans, our report suggested there was considerable scope at secondary and higher levels for reductions of unit costs of education in ways which would not seriously affect the quality of schooling:

(a) by increasing the size of small classes and small schools (but without altering the size of the largest classes);

(b) by changing the salary structures of secondary and higher qualified teachers, not as an isolated case, but as part of a general revision of all salaries of educated persons. The difficulties of this are obvious, but some revision may be possible at a time of general price increases and increasing difficulty which educated persons, at least secondary school leavers, have in finding jobs;

(c) by reducing capital costs per student.

\section{Lessons for the Future}

What lessons can be drawn for future work in manpower planning? First, it seems obvious that much greater attention must be paid to the manpower implication of the structural problems that have appeared and are increasingly likely to appear over the next decade. These include, particularly, the tendency for income distribution to become more unequal (in part because of the increasing numbers of educated personnel), the relatively slow growth of wage earning employment as compared with the rate of growth of the labour force, and the tendency for the rural-urban gap (or gaps) to widen. Manpower planners should consider measures to deal with this whole set of problems with their direct implications for the quantities, types, location, uses and incomes of skilled and educated workers.

Although in our view long-term manpower projections at the macro-level are still of some value for purposes of analysis and development planning within this changing context, only limited insights can be expected from them and the balance of effort should be shifted to micro studies, for instance at the sectoral or occupational level. Detailed studies of clusters or related occupations - for example of medical occupations, of the occupations involved in government administration, or clerical occupations, of the occupations in the building and construction sector (engineers, architects, technicians) etc. - 
could greatly contribute to an assessment of the adequacy of the training and education of the skilled and educated workers in these occupational groups. Such studies would have to take account of quality as well as quantity, of informal as well as formal education and training, of the efficiency with which the persons concerned are employed, of the adequacy of the labour market in allocating persons between jobs and of the whole range of incentives and institutional arrangements involved in the employment of the skilled and educated manpower in the occupational groups concerned. They should give particular weight to issues of employment and income distribution and to their links with education and relevant skills, especially in rural areas. And finally they should consider what structure of institutions and incentives would help win support for effective change.

Inevitably studies on these lines would be more varied and less uniform than earlier manpower surveys. They would rely more heavily on impressions obtained from interviews than on statistical calculations. They would draw upon the skills of the sociologist and the social psychologist and administrator as much as on those of the economist. They might well start with problems of job analysis and proceed from there to the question of skills needed, and then to specification of the training required. This does not mean embarking on a perfectionist solution. We fully recognize that the staff available to undertake such studies will continue to be limited. In our view useful studies on these lines could be undertaken and completed in many of the smaller African countries. In other words, they would be well within the resources of many of the manpower planning units and, in all, not much more burdensome than the manpower planning already engaged in. But their results would be likely to be of much greater value for policy and their benefits far greater than the costs. 